\title{
A pilot project: evaluating community nurses' knowledge and understanding of the Adult Support and Protection (Scotland) Act 2007
}

Martin Campbell and Dionne Chamberlin

Martin Campbell is based in the School of Psychology, University of St Andrews, St Andrews, UK.

Dionne Chamberlin is based at Streets Ahead Borders, Duns, UK.

\begin{abstract}
Purpose - This paper's aim is to evaluate understanding and knowledge of the Adult Support and Protection (Scotland) Act 2007 in a sample of community nurses working in learning disability services in Scotland.

Design/methodology/approach - Ten community nurses who worked in learning disability services in one NHS area were tested at two time points, four months apart using a questionnaire designed for this study by researchers and practitioners. Level of previous national training in the Adult Support and Protection Act and length of time working with people with learning disabilities were recorded. Three domains of adult protection were included in the questionnaire: Principles of the Act and definitions; Adults at risk of harm; Protection, assessment, removal and banning orders.

Findings - Questionnaire scores varied widely overall and across the three domains. There was no correlation between individual scores and training or length of work experience. The level of knowledge was below what might have been expected for this group, given the level of training and experience. Carefully designed verification of the impact of nationally approved adult support and protection training is needed. Originality/value - There is an absence of research in evaluating the impact of the approved Scottish Government training materials on staff knowledge and understanding of the 2007 Act, with staff attendance being taken as the main measure of training compliance. This was a small scale pilot study and recommendations are made for the scope and methods of evaluation.
\end{abstract}

Keywords Adult protection, Safeguarding, Evaluation of training, Nurses, United Kingdom, Social care, Learning disabilities, Legislation

Paper type Research paper

\section{Introduction}

The Adult Support and Protection (Scotland) Act 2007 was introduced by the Scottish Government to organise a more coordinated approach to supporting and protecting adults who may be at risk of harm or neglect. Statutory, voluntary and private providers are obliged to develop their own operating procedures to anticipate, prevent and respond to harm or abuse. This legislation was partly in response to a long history of abuse and neglect of adults with learning disabilities in managed care settings in Scotland and elsewhere in the UK (Social Work Services Inspectorate and Mental Welfare Commission, 2005; Scottish Public Services Ombudsman, 2010; Cornwall County Council, 2008; Flynn, 2007; Healthcare Q1 Commission, 2007; Mencap, 2007; DoH, 2009).

There are some parallels here between the 2007 Act in Scotland and the Mental Capacity Act (MCA) 2005 for England and Wales, which came into force in 2007; both were followed with the formation of adult protection committees and the development of national training initiatives, although in England and Wales, adult protection committees were already in development following the introduction of policy guidance from 2000 onwards.

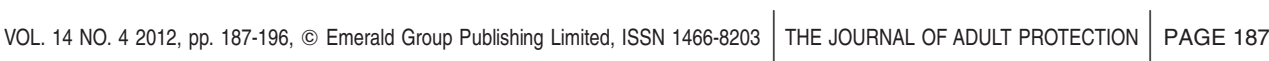


Under the 2007 Act individual staff working with adults with learning disabilities and other adults at risk of harm are obliged to report suspicions of all forms of harm, neglect, or abuse, for example physical, psychological, financial or sexual abuse, neglect, discrimination or withholding information about entitlements.

Adults at risk are defined in the Act as "adults aged 16 or over who:

- are unable to safeguard their own well-being, property, rights or other interests;

- are at risk of harm; and

- because they are affected by disability, mental disorder, illness or physical or mental infirmity, are more vulnerable to being harmed than adults who are not so affected".

This applies in all settings, including the family home, residential care, day services, work and public places. The Act places a joint duty on local councils, NHS trusts, police and other agencies to investigate suspected cases of adults at risk. The aim of the measures outlined in the Act is effective early intervention where abuse is suspected and proactive measures to reduce the probability of abuse in the first place. The local authority "must make inquiries about a person's well-being, property or financial affairs if it knows or believes: (a) that the person is an adult at risk, and (b) that it might need to intervene in order to protect the person's well-being, property or financial affairs".

To facilitate implementation of the Act, the Scottish Government (2007) produced core training materials at three levels, to address the training requirements for different levels of knowledge and skills. Level 1 training, recommended for all NHS staff, is basic awareness, knowledge and understanding of adult support and protection. Level 2 training is for those staff who have contact with people with learning disabilities. It requires good awareness of adult protection issues, and an operational knowledge and understanding of the Act, to be able to respond appropriately whilst providing support and/or treatment. It is aimed at home care, care home, support and housing staff, day care staff, hospital and community nurses and allied health professionals. The training requires supplementary full awareness training. Level 3 training is intended for council officers, health service managers, police, other specialists and staff from regulatory bodies. The adult support and protection training has been given a high priority for training in learning disability provider organisations and is included in induction programmes, as well as ongoing in-service training. A total of $£ 7.8 \mathrm{~m}$ was made available to authorities for the period October 2008 to March 2009 to assist with implementation of the Act, including training. NHS authorities and their partner organisations have been involved in the development and implementation of training strategies. The main strategy during the first year of the Act was to "train the trainers" by targeting specialist staff in organisations, provide them with Level 3 training, and then organize for these staff to provide Level 1 and Level 2 training to other staff in their organisations (Scottish Government, 2008). This is a similar model to that adopted in England and Wales following the publication of the Department of Health, No Secrets and In Safe Hands policy guidance in 2000 (McKeough, 2009). It has been argued that training in relation to No Secrets may have increased competence in responding to abuse that has already occurred, but it has not increased the probability of protecting individuals from the onset of abuse (Marsland et al., 2007). There is a basic belief, however, that staff training will improve staff performance. The Health Select Committee (2004) report, for example, asserted that training of staff could increase the identification and reporting of abuse evidence from previous evaluation of similar training for staff working with people with learning disabilities has reported mixed results however (Hogg et al., 2001; Cullen, 1988; Hastings, 1996; Taylor and Dodd, 2003).

The Scottish Government training materials are carefully planned to cover the core elements of the Act and the materials are publically available as a series of PowerPoint presentations with supporting notes (Scottish Government, 2007). What is noticeably lacking in this important process is any means of verifying whether staff awareness, knowledge and understanding have increased as a result of the training in the short or in the long term. Staff attendance has been taken as the main measure of training compliance. In the abuse and death of Steven Hoskin (Cornwall County Council, 2008) the importance of verifying the impact of training has been emphasised:

PAGE $188 \mid$ THE JOURNAL OF ADULT PROTECTION $\mid$ VOL. 14 NO. 42012 
2,000 health and social care staff and volunteers in Cornwall were being trained annually in safeguarding without any evidence of whether attending had an effect on practice (Pike et al., 2010, p. 33).

Training materials have also been produced to support the Mental Health Capacity Act in England and Wales (Department of Health, 2007) and a number of recommendations have been made concerning the implementation of the Act (Manthorpe and Samsi, 2009; Manthorpe et al., 2008). Whilst research evidence suggests that there is a combination of variables which contribute to the overall effectiveness of arrangements to safeguard adults from abuse (Commission for Social Care Inspection (CSCI) Report, 2008b) staff training is key (Faulkner and Sweeney, 2011). CSCI Report (2008a, p. 62) found a correlation between staff training on safeguarding and the quality rating of the service at that time. They found that access to good quality training and the reinforcement of that training in day-to-day practice is the "area that needs most improvement in regulated services". An audit tool has been introduced to improve quality control in the implementation of the MCA (SCIE/BPS, 2010). Knowledge of the MCA has been evaluated in the context of services to people with dementia:

considerable variation in understanding of terms and principles of the MCA was found. Few participants were aware of specific legislative points and offered "common sense" explanations for their actions and decision-making. This level of knowledge may not meet regulators' requirements or the needs of residents (Manthorpe et al., 2010).

Previous research looking at staff knowledge about adult protection highlighted reasons for low levels of reported abuse with learning disabilities and other service user groups (Taylor and Dodd, 2003). A variety of recommendations have been made, including several relating to training requirements. Training should be responsive to the identified needs for information and knowledge of those staff being trained (Dodd and Lamb, 2004). In this major study, involving interviews with 150 members of staff who were employed by statutory and voluntary sector organisations dealing with vulnerable adults, one of the main recommendations was:

devising ways in which the training can be better evaluated in order to establish the effectiveness and impact of this style of training, including a review of the evaluation format; follow-up of learning outcomes with participants and any deficiencies that need to be addressed should also be considered (Dodd and Lamb, 2004).

In addition there was a recommendation for mandatory training updates on abuse issues every two years. Similarly, Slater (2002) described a local strategy for implementing No Secrets training, and Richardson et al. (2002) found a lack of knowledge in dealing with elder abuse.

Community nurses working in learning disability services are in a prime position to implement adult protection (Davies and Jenkins, 2004). The pilot research project reported here investigated nurse knowledge and understanding following national core training in Scotland. The research project involved collaboration between a voluntary sector organisation which provides services to adults who have learning disabilities and significant and complex needs, and the School of Psychology, University of St Andrews.

The aims of the study were as follows:

- To develop a suitable research design for use in evaluating nursing staff understanding and knowledge of the Adult Support and Protection (Scotland) Act 2007.

- To increase the research capacity of the participating organisation to conduct knowledge and training evaluations, with a view to improving quality of service user care.

- To make recommendations for further evaluation of training.

The intended practice outcomes were:

- Improved effectiveness of training within the NHS area, to benefit adults with learning disabilities, as a result of increased research and evaluation capacity.

- Knowledge transfer to the voluntary sector partner organisation and dissemination of knowledge in community nurses and other staff. 
Participants were community nurses working in one NHS area (population approx. 112,500), and employed either by the NHS or by voluntary sector organisations. 12 nurses agreed to participate initially, and ten completed both stages of the research. The work and training experience of participants is given in Table I.

There was a wide range of experience and training. For example, one participant reported having had no training in adult support and protection, and one participant was undertaking a university level postgraduate course in adult support and protection. The majority of participants (six) had received Level 2 training.

\section{Measures}

A written test of knowledge and understanding was jointly developed by University of St Andrews and partner organisation staff. This was based on the Level 2 Scottish Government training materials and consisted of 30 multiple choice and true/false questions to test participant knowledge and understanding in the domains of:

- Principles of the Act and definitions.

- Adults at risk of harm.

- Protection, assessment, removal and banning orders.

The test had a maximum overall score of 30 and questions on the areas identified as principles of the Act and definitions $=13$ questions; adults at risk of harm $=12$ questions; protection, assessment, removal and banning orders = five questions.

The questionnaire was administered on two separate occasions (see Section Procedure).

\section{Procedure}

The research was sequenced as follows in Table II.

\section{Results}

It is important to emphasise that in such a small, non-random sample of staff, results are indicative only. There was considerable variability in both individual scores and on the frequency of correct responses to individual questions.

Individual scores for each of the ten participants on each questionnaire are shown in Figure 1. The maximum possible score was 30 per questionnaire.

Scores ranged from 13 to 24 . The mean average score overall (both questionnaires) was 16.6 (55 percent). There was no significant difference between individual scores on first and second questionnaires (Wilcoxon Signed-rank test).

To test for a relationship between mean average questionnaire scores for each participant and level of training a simple one-tailed $t$-test was used. To test for a relationship between mean average questionnaire scores for each participant and length of time working with adults with learning disabilities a Pearson's test of correlation $(r=0.129)$. There was no significant relationship between scores and training or length of service.

Table I Experience and level of training of participants

Number of years working with adults with learning disabilities

Previous training in adult support, protection and safeguarding

PAGE $190 \mid$ THE JOURNAL OF ADULT PROTECTION $\mid$ VOL. 14 NO. 42012 
Table II Sequence of research

\begin{tabular}{ll} 
Month & Tasks \\
\hline 1 & Ethical approval agreed (UTREC and NHS Clinical Governance Committee). \\
& Recruitment of nurses \\
& Development of questionnaire, based on Level 2 Scottish Government adult \\
& support and protection training materials. Questionnaire jointly developed by the \\
School of Psychology, University of St Andrews and voluntary sector organisation, \\
Streets Ahead Borders. Test-retest reliability established via a sample of ten \\
students who had recently completed a postgraduate certificate qualification in \\
"Adult support, protection and safeguarding". Reliability was acceptable \\
(Pearson's correlation coefficient = 0.712). Questionnaire administered to all \\
participants under test conditions (no access to written materials or other sources of \\
external information). Content validity was agreed between research staff, based on \\
sampling of the Scottish Government national training materials (Scottish \\
Government, 2007) \\
Analysis of questionnaire results. Analysis of scores for correlations with level of \\
experience and/or training individually and overall \\
Randomisation of order of 30 questions in questionnaire to produce second \\
questionnaire \\
Second questionnaire administered to all participants under test conditions. Further \\
analysis to investigate correlations between total scores and experience and \\
training of participants. Feedback on scores to participants \\
Final statistical and descriptive analysis. Report to funding organisation, Queens \\
Nursing Institute Scotland
\end{tabular}
Nursing Institute Scotland

\section{Figure 1 Individual participant scores}

$\mathrm{n}=10$; Total Scores for participants for questionnaires $1 \& 2$ Max possible $=30$

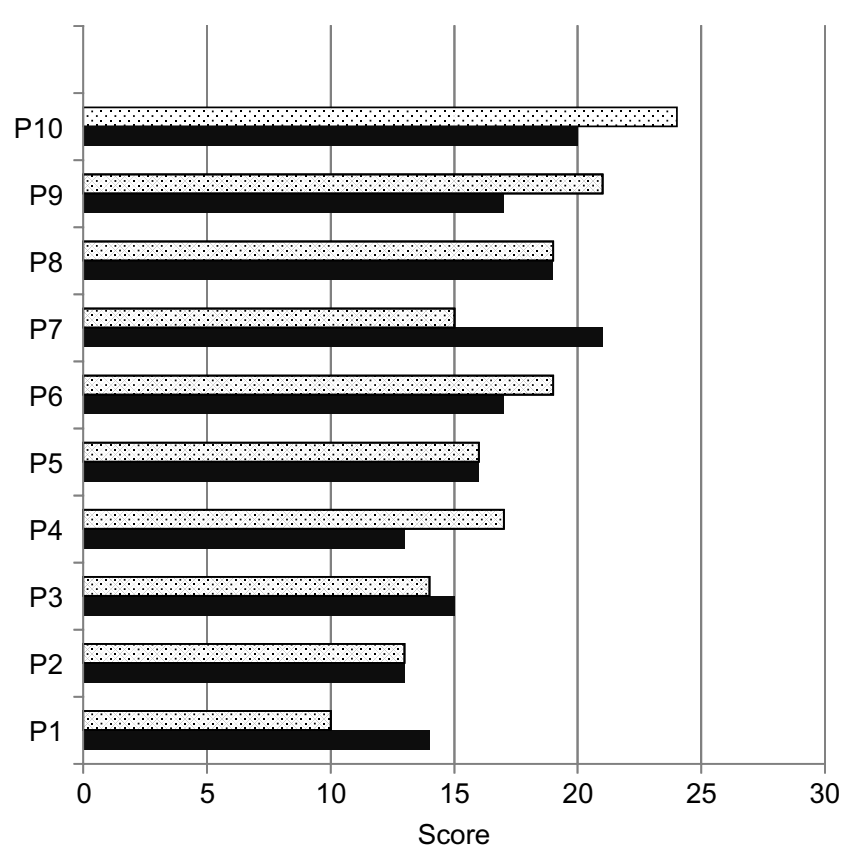

․․ Correct Answers 1st Questionnaire

- Correct Answers 2nd Questionnaire 
There was considerable variation in the frequency of correct answers for individual questions, and across the three areas or domains of adult protection in the questionnaire, i.e. principles of the act and definitions; adults at risk of harm; protection, assessment, removal and banning orders (Figure 2).

Scores on questions related to protection, assessment, removal and banning orders were poorest; each of the five questions was answered 20 times in total and the total correct answers for the group was 46 percent overall. The 12 questions related to adults at risk of harm were answered correctly 55 percent of the time, and the 13 questions related to principles of the Act and definitions were answered correctly 47 percent of the time.

\section{Discussion}

This was a partnership in research study, funded by the Queens Nursing Institute, Scotland. The aims of the pilot study were to investigate the understanding and knowledge of the Adult Support and Protection (Scotland) Act 2007 in a sample of community nurses working in learning disability services in one NHS area, and to use partnership working to increase the research capacity of the participating organisation for any further evaluation of training.

Participants' understanding and knowledge of the Adult Support and Protection (Scotland) Act 2007 varied widely, and this finding was not related to work experience, or to level of previous training in Adults Support and Protection. A 30-item questionnaire was completed by participants at two different time points, three months apart. Scores on the questionnaire overall averaged 55 percent for all participants, representing a range of $40-73$ percent for individual participants.

There was no correlation between years of experience and individual scores on the two questionnaires. There was no relationship between scores on this questionnaires and the level of participant's previous training. The individual mean average scores were all above 50 percent overall for both questionnaires but were below what might be have been predicted for this group, given the levels of training and experience.

The Adult Support and Protection (Scotland) Act 2007 has set out the legislative context in which local authorities, NHS organisations and voluntary sector providers are expected to protect known adults at risk, and improve service design and operational measures to minimise harm and abuse to adults in the future. To do this, relevant personnel need to be competent and confident in a range of skills.

There may be a theory-practice gap between what is known about effective adult protection and what public services and their practitioners actually do on a day-to-day basis.

Figure 2 Correct responses on individual questions

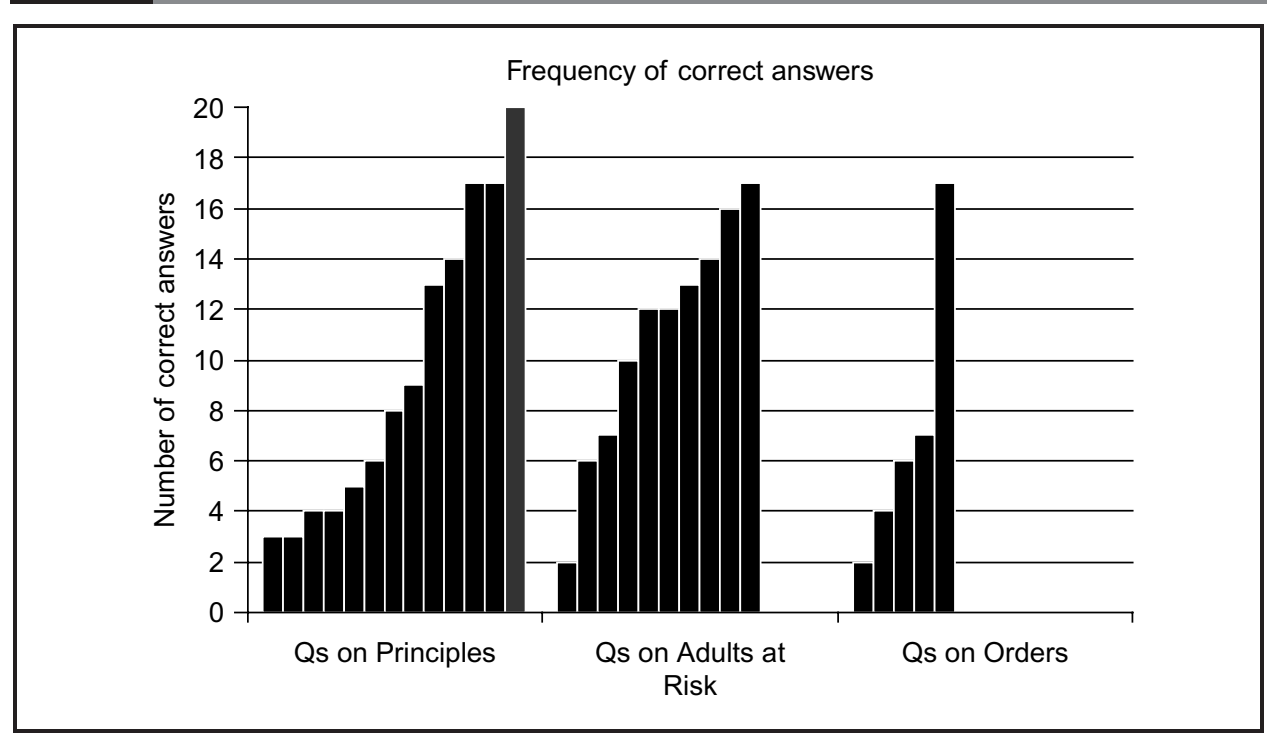


Previous research suggests that this gap may be due to number of factors including a lack of organisational structure (Baum and Lyngaard, 2006), inadequate training (Campbell, 2007), and lack of basic knowledge (Hastings, 1996). All of these factors may be precluding the effective implementation of the Adult Support and Protection (Scotland) Act 2007.

Scores on the questionnaires are indicative only. It is not possible to extrapolate from this small group to the larger population of practitioners. There are, however, some lessons to be learned for researchers attempting to evaluate training in this area:

- Participants in this pilot were not time restricted in completing the questionnaires and this may be a confounding factor.

- Questionnaires were completed under test conditions in a variety of work settings. Each participant may have had different types of exposure to adult protection measures, before completing the first questionnaire and in-between completing the first and second questionnaires.

- The time delay between completing Level 2 adult support and protection training and completing the questionnaires was not recorded for each person, and varied between six and nine months.

- Although the area of protection, assessment, removal and banning orders was highlighted as an area where knowledge and understanding was weak there were only five questions from a total of 30 on this topic and a more balanced evaluation questionnaire is needed.

- True/false questions scored higher than multiple choice questions and differentiated the highest scoring items from lower scoring items in the questionnaire overall. Research suggests that the multiple choice questions have greater experimental reliability than true/false questions, although both type of questions have equal validity in testing knowledge (Frisbie, 1973).

- The design of the questionnaire was achieved through collaboration between a university and a voluntary sector organisation, which increased face validity. Informal feedback from participants indicated that the questionnaire was relevant to day-to-day practice.

One principle of the adult support and protection legislation is the development of more effective procedures, incorporated in policy, to protect adults from harm, through an increased awareness of the research, statistical and trend evidence of harm to those most at risk. Whilst the issue of staff competence of community nurses is crucial, training in different aspects of adult protection with different professional groups and different groups of people at risk is required for the development of any comprehensive adult protection strategy (Aylett, 2009). For this reason, testing knowledge of community nurses only may not give a representative evaluation of how well adults at risk are protected in any given area.

There is also the "elephant in the room" of staff training: is it possible for all staff who need them to acquire the range of complex skills necessary to implement effective adult protection? This is particularly relevant in settings where staff are working alone, or where

Q1 there is little specialist support readily available (Campbell, 2010), which is typical of small scale models of service. Similarly, as "self-directed" services become more widespread it is not clear whether there will be enough staff with the right motivation, values, attitudes and skills to meet the demand (Mansell, 2010) and this potential shortage should be factored into workforce development and service planning.

This pilot study suggests that carefully designed evaluation of the effectiveness of training on a larger staff population may be needed to more accurately verify the impact of adult support and protection training. Collaboration between researchers and practitioners may be mutually beneficial, in designing more "diagnostic" evaluations that combine legislative knowledge of the Act with the more applied knowledge that would be expected in practical work settings. For training purposes it will be both more efficient and more effective to specify the areas where knowledge and understanding could be improved, and how. 
Aylett, J. (2009), "A model and strategy for multi-agency adult protection training in Kent and Medway",

Baum, S. and Lyngaard, H. (2006), Intellectual Disabilities: A Systemic Approach, Karnac, London.

Campbell, M. (2007), "Staff training and challenging behaviour: who needs it?", Journal of Intellectual Disabilities, Vol. 11 No. 2, pp. 143-56

Cornwall County Council (2008), Findings of Serious Case Review: Steven Hoskin, Health and Adult Social Care Overview and Scrutiny Committee, Cornwall County Council, Truro.

CSCI Report (2008a), Raising Voices: Views on Safeguarding Adults, Commission for Social Care Inspection, London.

CSCI Report (2008b), Safeguarding Adults: A Study of the Effectiveness of Arrangements to Safeguard Adults from Abuse, Commission for Social Care Inspection, London.

Cullen, C. (1988), "A review of staff training: the emperor's old clothes", The Irish Journal of Psychology, Vol. 9, pp. 309-23.

Davies, R. and Jenkins, R. (2004), "Protecting people with learning disabilities from abuse: a key role for learning disability nurses", The Journal of Adult Protection, Vol. 6 No. 2, pp. 31-41.

Department of Health (2007), Mental Capacity Act 2005: Training Materials, Social Care Workforce Research Unit, King's College, London, available at: www.dh.gov.uk/en/Publicationsandstatistics/ Publications/PublicationsPolicyAndGuidance/DH_074491

Dodd, K. and Lamb, L. (2004), "Recommendations into practice: implementing the results of local research into adult protection", The Journal of Adult Protection, Vol. 6 No. 1, pp. 20-6.

Faulkner, A. and Sweeney, A. (2011), Prevention in Adult Safeguarding: A Review of the Literature, Social Care Institute for Excellence, London.

Flynn, M. (2007), "Unlearned lessons from the Healthcare Commission's investigation into the service for people with learning disabilities provided by Sutton and Merton Primary Care Trust", The Journal of Adult Protection, Vol. 9, pp. 21-6.

Frisbie, D.A. (1973), "Multiple choice versus true false: a comparison of reliabilities and concurrent validities", Journal of Educational Measurement, Vol. 10 No. 4, pp. 297-304.

Hastings, R.P. (1996), "Staff training and management in services to people with learning disabilities: an annotated bibliography", British Journal of Clinical Psychology, Vol. 35 No. 3, pp. 480-2.

Healthcare Commission (2007), Investigation into the Service for People with Learning Disabilities Provided by the Sutton and Merton Primary Care Trust, Healthcare Commission, London.

Health Select Committee (2004), The House of Commons Health Select Committee on Elder Abuse, Health Select Committee, London.

Hogg, J., Campbell, M., Cullen, C. and Hudson, W. (2001), "Evaluation of the effect of an open learning course on staff knowledge and attitudes towards the sexual abuse of adults with learning disabilities", Journal of Applied Research in Intellectual Disabilities, Vol. 14, pp. 12-29.

McKeough, C. (2009), "Reflections and learning from adult protection policy development in Kent and Medway", The Journal of Adult Protection, Vol. 11 No. 1, pp. 6-12.

Mansell, J. (2010), Raising Our Sights: Services for Adults with Profound Intellectual and Multiple Disabilities, Tizard Centre, University of Kent, Canterbury.

Manthorpe, J. and Samsi, K. (2009), "Implementing the Mental Capacity Act 2005: challenges for commissioners", Journal of Integrated Care, Vol. 17 No. 3, pp. 39-47.

Manthorpe, J., Rapaport, J. and Stanley, N. (2008), "Expertise and experience: service users' and carers' views on the Mental Capacity Act 2005", British Journal of Social Work, Vol. 39 No. 5, pp. 884-900.

Manthorpe, J., Samsi, K., Heath, H. and Charles, N. (2010), '“Early days': knowledge and use of the Mental Capacity Act 2005 by care home managers and staff", Dementia, Vol. 10 No. 3, pp. 283-98. 
Marsland, D., Oakes, P. and White, C. (2007), "Abuse in care? The identification of early indicators of the abuse of people with learning disabilities in residential settings", The Journal of Adult Protection, Vol. 9 No. 4, pp. 6-20.

Mencap (2007), Death by Indifference, Mencap, London.

Pike, L., Indge, R., Leverton, C., Ford, D. and Gilbert, T. (2010), "Bridging the gap between learning and practice: from where we were to where we are now", The Journal of Adult Protection, Vol. 12 No. 2, pp. 28-38.

Richardson, B., Kitchen, G. and Livingston, G. (2002), "The effect of education on knowledge and management of elder abuse: a randomised controlled trial", Age and Ageing, Vol. 31, pp. 335-41.

SCIE/BPS (2010), Audit Tool for Mental Capacity Assessments, Social Care Institute for Excellence/British Psychological Society, Leicester.

Scottish Government (2007), "Adult support and protection: national training materials", available at: www.scotland.gov.uk/Topics/Health/care/adult-care-and-support/legislation/ASPtraining

Scottish Government (2008), Towards Implementation of the Adult Support and Protection (Scotland) Act 2007, 3rd ed., Newsletter, Adult Care and Support Division, Scottish Government, Edinburgh.

Scottish Public Services Ombudsman (2010), Report on Tayside NHS Board, Report Number: 200802400, Report Date: 24 March 2010, Scottish Public Services Ombudsman, Edinburgh.

Slater, P. (2002), "Training for no secrets: a strategic initiative", Social Work Education, Vol. 21 No. 4 pp. 437-48.

Social Work Services Inspectorate and Mental Welfare Commission (2005), No Fears as Long as We Work Together - Follow Up Joint Inspection of Scottish Borders Council and NHS Borders: Verifying Implementation of Their Action Plan for Services for People with Learning Disabilities, Scottish Government, Edinburgh.

Taylor, K. and Dodd, K. (2003), "Knowledge and attitudes of staff towards adult protection", The Journal of Adult Protection, Vol. 5, pp. 26-32.

\section{Further reading}

Department of Health and Home Office (2000), No Secrets: Guidance on Developing and Implementing Multi-agency Policies and Procedures to Protect Vulnerable Adults from Abuse, Department of Health, London.

WAG (2000), In Safe Hands, Welsh Assembly Government, Cardiff.

\section{Corresponding author}

Martin Campbell can be contacted at: mc1@st-andrews.ac.uk 


\section{Author Queries}

JOB NUMBER: 150531

JOURNAL: JAP

Dear Author

Please address

(n)
on the proof for your convenience.

Thank you for your cooperation

Q1 The references DoH (2009) and Campbell (2010) have been cited in text but not
provided in the list. Please check. 